\title{
Aporías al consenso moral en el mundo unipolar
}

\author{
Jairo Vargas-León ${ }^{*}$
}

* Doctorando en Derecho, Universidad Libre, Bogotá, Colombia. Profesor de Derecho administrativo colombiano, Universidad Cooperativa de Colombia, Bucaramanga, Colombia. Correo electrónico: jairo.vargasl@campusucc.edu.co

Recibido: 11 de agosto del 2014 Aprobado: 18 de septiembre del 2014

Cómo citar este artículo: Jairo Vargas-León. Aporías al consenso moral en el mundo unipolar. DIx 20. Diciembre 2014. Pág. 85. doi: http://dx.doi. org/10.16925/di.v16i20.830

\section{Resumen}

El presente artículo examina la relación entre derecho y moral, en particular el desarrollo de las aporías que surgen en dicha configuración. Esto, en el marco de distintos escenarios, tanto en lo local como en lo global, en los cuales se contrapone un problema del que no es posible apartarse, no es posible soslayar, ni se puede posponer. Pese a que la teoría jurídica presupone que estas aporías son resueltas, nada más lejano a esta proposición, estas subyacen en el texto, sin que sea absuelta la verdadera dimensión que ostentan. ¿Es posible dotar al derecho de inmunidad frente a una aporía?

Palabras clave: aporía, consenso, ley, moral, pluralismo.

\section{Dilemmas for Moral CONSENSUS in a Unipolar World}

\section{Abstract}

This article examines the relationship between law and morality and particularly the dilemmas that arise from that configuration. It uses diverse scenarios, both at the local and global levels, to address a problem that cannot be ignored, avoided or postponed. Even though legal theory assumes that these dilemmas have been settled, that is far from the case because they underlie the text without their true dimension having been resolved. Can the law be given immunity in the face of a dilemma?

Keywords: dilemma, consensus, law, morality, pluralism.

\section{APORÍAS AL CONSENSO MORAL NO MUNDO UNIPOLAR}

\section{Resumo}

El presente artigo examina la relação entre direito y moral, en particular el desenvolvimento das aporías que surgen en dicha configuração. Esto no marco de distintos escenarios, tanto en lo local como en lo global, en los cuales se contrapone un problema del que no es posible apartarse, no es posible soslayar, ni se puede posponer. Pese a que la teoría jurídica presupone que estas aporías son resueltas, nada más lejano a esta proposição, estas subyacen no texto, sin que sea absuelta la verdadera dimensión que ostentan. ¿Es posible dotar al direito de inmunidad frente a una aporía?

Palavras-chave: aporía, consenso, ley, moral, pluralismo. 


\section{INTRODUCCIÓN}

La aporía es la ausencia de camino o, a contrario sensu, un camino sin salida, aquello que no puede resolverse. Viehweg señalaba que el término aporía designa precisamente una cuestión que es acuciante e ineludible, la falta de un camino, la situación de un problema que no es posible apartar. ${ }^{1}$ Hay casos en los que no es posible absolver plenamente la problemática que se plantea, $y$ esta reaparece en una forma nueva. En el caso del derecho, esta disciplina se ve continuamente perturbada por este problema y no se libera de él, lo cual plantea si el derecho resuelve los problemas, los difiere, los soslaya o sencillamente se obnubila por su reconversión. ¿De qué manera el derecho sigue coexistiendo con estas aporías?

En contraposición al problema planteado, surge la necesidad de propiciar la idea de consenso, la cual objetiva el juicio moral. Frente a ello cabe considerar el planteamiento de Rawls, ${ }^{2}$ quien propone un valor moral cuando los representantes deliberan en total ignorancia en la posición original, de manera que sus conclusiones tienen valor de verdad moral a partir del multilateral acuerdo en un determinado pueblo, cultura y tiempo. En virtud de ello, las personas que nacerán y se insertarán en esa sociedad con instituciones básicas ya conformadas en representación de lo que se ha gestado como justo, desearán suscribir a ello en condiciones de equidad; el hecho de predecir que lo desearán no es más que reconocer que es deseable lo moralmente válido.

Respecto a la categoría moral, para Kant, "la ley es un juicio que contiene un imperativo categórico. Cuando un ser humano actúa conforme al principio subjetivo que el sujeto se ha puesto como regla, actúa conforme a la máxima solución necesaria.". Esto último es en el hombre resultado de su libre arbitrio. En cambio "la voluntad que solo deriva de las leyes no es libre, porque no deriva de conductas sino inmediatamente de la legislación para las máximas de las conductas solución necesaria". ${ }^{4}$

1. Theodor Viehweg. Tópica y JURISPRUDEncia. Editorial Taurus. (1964). Pág. 31.

2. John Rawls. Teorí́a De la JUsticia. Editorial Fondo de Cultura Económica. (1995). Pág. 26.

3. Immanuel Kant. Metafísica de las costumbres. Editorial Porrúa. (2001). Pág. 62.

4. Id., pág. 63.
Un principio moral nos obliga a obedecer la ley. Sin embargo, queda aún por determinar lo que dicha ley es en sí, y si un ser humano puede ser considerado como moral sólo debido a que respeta la ley. La regulación moral proviene de la conciencia y este origen es independiente de si las reglas morales de dos personas son las mismas o distintas. Es muy diferente, por ejemplo, el temor a la culpa cuyo ámbito corresponde a la sanción interna, al temor a la censura social o el temor a la cárcel, los cuales se ubican en la esfera de las sanciones externas, aunque se puedan experimentar al tiempo. Son distintas las emociones de culpa, de vergüenza y de temor a la multa o a la cárcel.

Para Kant, la moralidad tiene pretensión de universalidad, pero es mucho más modesta y más limitada que la universalidad de las ciencias. Y esa pretensión de algún modo es neutra frente a la pregunta de si los demás llegan a actuar moralmente o no, o si interpretan o no de la misma manera qué significa actuar moralmente, o si reconocen o no la validez de la norma moral que la persona se auto-impone.

No obstante lo formulado por Kant, la aporía en su pensamiento se hace presente en la versión del clásico acertijo del "Asesino en la puerta" planteado por San Agustín, ${ }^{5}$ cuyo rigor no admitía duda. Un pobre hombre busca refugio en tu casa, y tú accedes a ocultarlo en tu hogar. Al cabo de un rato, el asesino llega y pregunta acerca del paradero del hombre que está buscando. ¿Qué es lo que haces? El sentido común nos dice que debemos mentir y decirle al asesino que ignoramos el paradero del otro hombre o que lo vimos encaminarse hacia otra parte. Pero un dogmático dirá que, dado que no debemos mentir bajo ninguna circunstancia, debes confesar al asesino que el hombre está oculto en tu propia casa. En el tema del asesino que pregunta si el hombre que pretende convertir en su víctima está en su casa, Kant ofreció un argumento en un ensayo concerniente a un supuesto derecho a mentir por motivos altruistas. En 1797, escribió:

Si por decir una mentira has prevenido un asesinato, te has hecho legalmente responsable por todas las consecuencias; pero si te has atenido rigurosamente a la verdad, la justicia no puede castigarte en modo alguno, cualesquiera que sean las consecuencias imprevistas. Después de que has contestado honestamente la pregunta del asesino acerca de si su víctima potencial está

5. Umberto Eco. El clásico acertijo del asesino en la puerta. EL Espectador. Febrero 19 de 2012. 
en casa, puede suceder que ésta haya huido de la casa para no toparse con el asesino y, en consecuencia, el asesinato no se comete. Pero si hubieras mentido y dicho que no estaba en casa cuando realmente se había escapado sin que tú lo supieras, y si el asesino se lo hubiera encontrado al salir y lo hubiera matado, tú podrías ser acusado justamente de su muerte. Porque si hubieras dicho la verdad tal como la conocías, quizás el asesino hubiera sido aprehendido por los vecinos mientras buscaba en la casa y, en consecuencia, el crimen se hubiera prevenido. Por tanto, quien diga una mentira, por más bien intencionada que ésta pueda ser, debe responder por las consecuencias, por más imprevisibles que éstas sean, y cumplir la condena por ellas incluso ante un tribunal civil. ${ }^{6}$

Ser pluralista no necesariamente implica ser relativista. Hoy parece necesario aceptar que pueden coexistir puntos de vista morales diversos fuertemente obligantes para las personas, cada cual en ejercicio de su autonomía moral. La diversidad de juicios morales no es incompatible con el hecho de que cada cual, dentro de las reglas que se impone, se exija la posibilidad de desear que tales reglas subjetivas puedan ser ley universal.

No se puede poner la moral por encima de la ley, ni la ley por encima de la moral. Al menos, así lo pensó y actuó, en consecuencia, Sócrates, fundador de la reflexión ética. En "Critón”, uno de los célebres diálogos, Platón hace referencia a esto.

Sócrates está preso a la espera de beber la cicuta, pero Critón y otros de sus amigos van a la cárcel y le dicen: "Eres libre de salir, hemos sobornado al carcelero". Él arguye: "Analicemos juntos, como siempre lo hacemos, qué es lo debido". Las leyes atenienses han permitido que los padres se unan en matrimonio, que lo engendren y lo eduquen, y él las ha aceptado con entusiasmo. ¿Ahora, cuando le son desfavorables, va a repudiarlas? Eso no es lo que ha enseñado.?

Comparecer ante el Tribunal de los quinientos lo pone en riesgo de morir, pero ese riesgo es precisamente de los que deben afrontarse. De no hacerlo incurriría en el vicio vergonzoso de la cobardía. Esta reflexión le

6. Immanuel Kant. Sobre un presunto derecho de mentir por filantropía. TEORÍA Y PRÁCTICA. Editorial Tecnos. (2006).

7. Sócrates y el buen ciudadano. El Espectador. Febrero 24 de 2012. Disponible en: http://www.elespectador.com/opinion/socrates-y-elbuen-ciudadano. permite a Sócrates afrontar el juicio y por ende su reclusión sin una sola duda.

\section{APORÍAS EN EL MUNDO CONTEMPORÁNEO}

El mundo contemporáneo abunda en ejemplos de trasgresión de la ley con justificación moral. En el 2010, Teresa Lewis fue ejecutada en el estado de Virginia con una inyección letal. Nadie fue castigado por su asesinato, porque había sido condenada a muerte legalmente. Fue encausada por el asesinato de su esposo y de su hijo adoptivo, lo que, por supuesto, era legal, y aquellos que la ejecutaron actuaron con la bendición de las autoridades. Entretanto, la iraní Sakineh Mohammadi Ashtiani, por su infidelidad, incurrió en adulterio y por ello fue sentenciada a morir lapidada; el castigo fue rechazado internacionalmente. Ante la solidaridad que generó la iraní, el presidente Mahmoud Ahmadineyad ha respondido a los exhortos occidentales de clemencia con una frase lapidaria: se quejan porque queremos matar legalmente a una mujer iraní, ¿acaso en Occidente se quejan cuándo matan legalmente a una estadounidense? Una objeción para la lógica de Ahmadineyad es que la estadounidense orquestó el asesinato de su esposo, mientras la iraní, Sakineh Mohammadi Ashtiani, sólo fue infiel. La estadounidense murió sin dolor, mientras la iraní corrió el riesgo de morir de forma brutalmente dolorosa. Una respuesta de este tipo implica dos cosas: mientras una adúltera no debería ser castigada con más que una separación legal, sin derecho a obtener beneficios derivados de la sociedad conyugal, es aceptable castigar a asesinos con la pena capital siempre y cuando el método de ejecución no sea muy doloroso.

En una sociedad que se precie de ser democrática, ni siquiera los asesinos deberían ser sentenciados a muerte. Las sociedades no deberían matar a sus ciudadanos, ni siquiera luego de un debido proceso, o si la ejecución es relativamente indolora. El mundo occidental se sensibilizó con la ejecución de la mujer iraní (en Europa hubo causa común para oponerse a la mentada ejecución). ¿Hubo la misma solidaridad, la misma presión para impedir la ejecución de la mujer condenada en el estado de Virginia? ¿Acaso se hubiera protestado con la misma intensidad si la Iraní hubiera sido condenada a morir por inyección letal? ¿Acaso nos 
indigna la lapidación o la ejecución de infractores del sexto mandamiento "No cometerás adulterio", en lugar del quinto "No matarás"?

Los seres humanos somos profundamente contradictorios, capaces de mucho amor y de un cinismo a ultranza. Estamos dispuestos a proteger con sumo cuidado a una ardilla al igual que a poner a cocinar una langosta viva, demolemos un ciempiés sin remordimientos y tildamos de bárbaro al que mata una mariposa. Similarmente, aplicamos una doble moral cuando enfrentamos dos sentencias controversiales: nos escandalizamos con una y soslayamos el alcance de la otra.

\section{A. ¿De qué pluralismo habla la sociedad global?}

El Consejo Constitucional francés consideró la ley que prohíbe vestir la burka en todo lugar público conforme a la Constitución de ese país, salvo en los lugares de culto abiertos al público. En Francia, la norma prohíbe llevar la burka en todo lugar público, incluida la calle, bajo una pena de hasta ciento cincuenta euros. Tal decisión constituye una abierta discriminación religiosa. Según el presidente Sarkozy, esa prenda que cubre a las mujeres musulmanas de cabeza a pies "no es bienvenida en la Francia laica". Sin embargo, lo que muestra la prohibición es que Francia es todo menos laica; si lo fuera, el Estado no se vería llamado a meterse en las manifestaciones religiosas voluntarias de la gente. La polémica ventila como lo que más mortifica a Occidente es aceptar que alguien se tape por gusto; la burka desafía la liberalidad de la que tanto se ufana Francia y evidencia los prejuicios culturales y religiosos en el país galo.

Sumado a la anterior referencia segregacionista, en el segundo semestre de 2010, Francia anunció el plan nacional de lucha contra el racismo. Sin embargo, ello contrasta con la decisión gubernamental de desmantelar los cerca de trescientos asentamientos "nómadas" (gitanos, manuches, vendedores de feria y trabajadores de circo), dispuestos en zonas céntricas del país. Con la idea de proteger el derecho a la seguridad, el Gobierno lanzó una ofensiva para enviar a sus naciones de origen a los "nómadas", provenientes de República Checa, Bulgaria y, en mayor medida, de Rumania y Hungría.

No obstante, el problema no es tan sencillo. El número de nómadas calculado por el Gobierno francés ronda los cuatrocientos mil, de quienes el $90 \%$ cuentan con nacionalidad francesa. La propuesta según la cual los inmigrantes pierden la nacionalidad francesa en caso de cometer delitos ha sido contemplada en la política gubernamental gala. ¿Acaso el lema de libertad, igualdad y fraternidad proclamado en la Revolución francesa refleja el espíritu democrático de la actual sociedad gala?

\section{b. ¿Qué pluralismo puede tolerar el Estado social de derecho?}

Interesante reflexión se desprende de la decisión histórica que tomó en tiempos recientes la Corte Suprema de Justicia de los Estados Unidos. Esta decidió que las acciones de un grupo radical religioso, el cual irrumpe en los funerales de soldados estadounidenses caídos en guerra con pancartas ofensivas que atribuyen esas muertes a la tolerancia con los homosexuales en las filas, están protegidas por la libertad de expresión. Tradicional ha sido la defensa que la Corte estadounidense y en general su sociedad ejerce sobre la Primera Enmienda de la Constitución de los Estados Unidos, la cual protege la libertad de religión, de expresión y de prensa al punto de impedir que el Congreso pueda tramitar ley alguna que las pretenda controlar. El caso que la Corte Suprema estadounidense resolvió no era nada fácil de enfrentar.

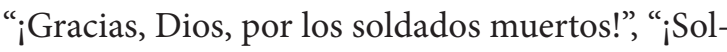
dados maricones!", eran algunos de los mensajes en las pancartas que portaban los manifestantes de la iglesia Bautista Westboro, durante los funerales del soldado Lance Matthew Synder, de 20 años, muerto en Irak. Ofendido y en medio de su dolor, Albert Synder, el padre del soldado, demandó al pastor Fred Phelps, conductor de la iglesia, por difamación y violación de la vida privada y de hecho. En un fallo de primera instancia ganó una indemnización cercana a los cinco millones de dólares por "daño moral". La decisión fue revocada por un tribunal de apelaciones y por eso el caso llegó a la Corte Suprema de Justicia.

Varios derechos estaban en juego en esta decisión. El derecho a la intimidad del soldado y de su familia, el derecho al respeto a una minoría como la comunidad homosexual y el derecho a la libertad de religión y de expresión de los manifestantes, cuando menos. Se trataba de uno de esos casos que el jurista español Manuel Atienza define como un caso trágico, esto es, aquel en que el juez se ve enfrentado a una decisión que en cualquier sentido supone daño para algún bien esencial. ¿Vale más la protección de una minoría como, 
en este caso, la comunidad homosexual, o el derecho a una creencia religiosa y a su expresión absolutamente libre? Y como corolario, ¿hace más bien a una sociedad permitir un debate tan agresivo contra una minoría que ponerle límites?

Dijo la Corte estadounidense en su sentencia: " $\mathrm{La}$ palabra es poderosa. Puede empujar a las personas a actuar, hacerlas llorar, de alegría o de tristeza, e infligirles, como en este caso, un gran sufrimiento. Pero no podemos responder a ese sufrimiento castigando a quien se ha expresado". Y agregó: "Como nación, hemos elegido un camino diferente, que es proteger la libertad de expresión, incluso cuando ella puede herir en cuestiones sociales, de modo que no ahoguemos el debate público". ${ }^{8}$ Ante todos los derechos esenciales en juego, la Corte se decidió, con ocho votos a favor y uno en contra, por proteger la libertad de expresión. Ello implica que en la tensión evidente entre dos derechos, la Corte estadounidense, fiel a su tradición jurisprudencial privilegió la categoría rawlsiana de la libertad en contraposición a la igualdad de derechos.

\section{ApORÍAS EN EL MARCO CONSTITUCIONAL COLOMBIANO}

\section{A. Aporía constitucional que confronta el Estado social de derecho}

Con el fin de desentrañar la aporía de carácter constitucional en Colombia, cabe remitirnos a la sentencia C-224 de 1994, en la cual se estudió la constitucionalidad del artículo 13 de la Ley 153 de 1887, cuyo precepto señala lo siguiente: "Artículo 13. La costumbre, siendo general y conforme con la moral cristiana, constituye derecho, a falta de legislación positiva". ${ }^{9}$

$\mathrm{Al}$ respecto, la Corte Constitucional, en el artículo 13 de la Ley 153 de 1887, ha conceptuado lo siguiente:

En primer lugar, la expresión 'moral cristiana' designa la moral social, es decir, la moral que prevalecía y prevalece aún en la sociedad colombiana... Y obsérvese que la costumbre, además de ser conforme con la

8. Editorial. Libertad de expresión y protección a las minorías. EL EsPECTADOR. Marzo 6 de 2011.

9. Ley 153 de 1887. Por la cual se adiciona y reforma los códigos nacionales, la ley 61 de 1886 y la 57 de 1887. Agosto 15 de 1887. Do N. ${ }^{\circ}$ 7151 y 7152 moral cristiana, debe ser general. Si es general y a la vez es conforme con la moral cristiana, es porque ésta es también la moral general". ${ }^{0}$

Pese a que la referencia a la moral cristiana tiene una connotación religiosa, en el marco de los pronunciamientos de la Corte se considera que no sería inconstitucional el artículo 13 de la Ley 153 de 1887, en razón a los siguientes supuestos:

- La religión católica es la de la mayoría de la población.

- Si a los adeptos que ostenta la iglesia católica se les contrapone la sumatoria de los de las demás iglesias cristianas existentes en Colombia, tal cantidad sería mínima respecto de la mayoría católica y distaría de la unanimidad sólo en un pequeño porcentaje.

- La Constitución, como todas las que han existido en Colombia, está basada en la democracia liberal, uno de cuyos principios es el reconocimiento de las mayorías.

Como corolario de lo anterior ha dicho la Corte lo siguiente:

No puede, en consecuencia, ser contraria a la Constitución una norma que se limita a reconocer la moral de las mayorías. El respeto a las minorías, también proclamado por el Liberalismo, no puede llegar hasta el extremo absurdo de pretender que las mayorías se sometan a ellas, o que renuncien al derecho de hacer prevalecer sus opiniones. Por ello, si en lugar de referirse a la moral de la mayoría de los colombianos, la ley pretendiera imponer a éstos la moral de una tribu indígena confinada en un remoto lugar de la selva amazónica, tal ley sí sería contraria a la Constitución". ${ }^{11}$

A contrario sensu, a tal afirmación cabe decir que la Corte ha equiparado la moral cristiana con la moral social, luego con ello niega la diversidad étnica y cultural de la nación, así como distorsiona los propios códigos de conducta de la moral cristiana al identificarlos con la moral social.

La Corte declaró constitucional una norma mediante la cual implementó que la costumbre praeter legem puede ser fuente de derecho, siempre y cuando

10. Corte Constitucional de Colombia. Sentencia C-224 DE 1994. (M. P. Jorge Arango Mejía; mayo 5 de 1994). Disponible en http://www. alcaldiabogota.gov.co/sisjur/normas/Norma1.jsp?i=15892

11. Id. 
ella sea general y conforme con la moral cristiana. Pero, a renglón seguido, considera necesario indicar, tanto en la parte motiva, como en la parte resolutiva de la sentencia, que la costumbre no tiene en realidad que ser conforme con la moral cristiana sino con la moral social.

En su precedente, la Corte ha reconocido, como en el derecho privado, que la costumbre podía ser local $y$, no obstante, servir como fuente de derecho, consideración que riñe abiertamente con la consagrada en la presente sentencia. Es de advertir que la Constitución de 1991 no invoca ninguna forma de moralidad religiosa, por lo cual la referencia a la moral cristiana establecida por la Ley 153 de 1887 constituye una discriminación contra otras formas de moralidad religiosa que pueden ser diversas a la cristiana pero conformes con la Constitución. Hay una falacia lógica en la que ha incurrido la Corte al enmarcar su argumento en una petición de principio por cuanto infiere que la moralidad cristiana, la moralidad social y los valores constitucionales coinciden integralmente.

Dos elementos trae la norma para que la costumbre, según lo dispone, constituya derecho: el primero, que sea general, es decir, que exista en cuanto tal en todo el territorio; y el segundo, que sea conforme con la moral cristiana. Luego, una costumbre puede ser general según la norma, y si no es conforme con la moral cristiana, no constituirá derecho, es decir, no podrá ser tenida como fuente del derecho. Esta interpretación invierte los efectos del carácter general que trae el precepto, para concluir que la moral general es también la moral cristiana. Es evidente el contraste con el nuevo orden constitucional, el cual otorga a las organizaciones religiosas no cristianas un tratamiento igualitario.

Si se tiene en cuenta que la moral universal, como lo dice la sentencia, es la que "prevalece en cada pueblo en su propia circunstancia", pero por otra parte, se afirma que "la moral es una pero sus manifestaciones cambian en razón de la diversidad de las sociedades en el espacio y en el tiempo", ${ }^{12}$ se está enunciando una oración en la cual el predicado contradice al sujeto, de la misma manera como la diversidad es contraria a la unidad.

La decisión mayoritaria no abordó en toda su dimensión la controversia que suscita en todos sus ámbitos la filosofía moral, sólo se limitó a defender una posición normativa en la exégesis de la Constitución colombiana; por tal razón, al emprender su razona-

12. Id. miento, el análisis de la diversidad moral y cultural es bastante precario.

El criterio de la mayoría es un instrumento para abordar conflictos y opiniones en asuntos que requieren de una posición unificada institucionalmente. La moral, en cambio, como manifestación individual o colectiva, en principio, no necesita de un procedimiento mediante el cual se busque la unificación o el consenso; cuando eso sucede, la cuestión moral se inserta dentro de un asunto jurídico o político. La moral no puede ser sometida al principio de las mayorías, simplemente porque ella no es negociable, ni siquiera conciliable. Una cosa es que la moral pueda ser el fundamento de una opción política, y otra diferente es que la política pueda ser el criterio para solucionar divergencias de tipo moral. Por eso, la utilización del principio normativo de las mayorías no tiene sentido cuando se aplica a un ámbito social e individual en el cual la Constitución postula la libertad.

Es relevante el contraste de la Corte Constitucional en la argumentación esgrimida en la sentencia C-224 de 1994, en contraposición a la de la sentencia C-373 de 2002. En esta última, señala lo siguiente:

Es por ello que los solos argumentos morales, desprovistos de incidencia en los derechos de los demás y de reconocimiento jurídico, son sustancialmente insuficientes para limitar la cláusula general de libertad. Y ello es claramente comprensible pues un modelo de organización política afincado en el multiculturalismo y con expreso reconocimiento del pluralismo jurídico no puede aspirar a imponer patrones morales. Por el contrario, las democracias deben partir del respeto de la diferencia como una exigencia de civilidad del mundo de hoy"."13

Tal argumento reconoce a la minoría como un soporte sustantivo del pluralismo que entraña una Constitución multicultural, y en la cual las expresiones étnicas, sociales, culturales, religiosas y políticas deben ser respetadas sin objeción alguna. En virtud de ello, la Corte Constitucional socava la democracia constitucional al sustentar la mayoría como uno de los fundamentos principales para sostener la constitucionalidad del lema según el cual la moral general es también la moral cristiana.

13. Corte Constitucional de Colombia. Sentencia C-373 DE 2002. (M. P. Jaime Córdoba Triviño; mayo 15 de 2002). Disponible en http://www. corteconstitucional.gov.co/relatoria/2002/c-373-02.htm 


\section{B. Aporía moral como efecto mediático}

A mediados de marzo del 2011, el jugador del Deportivo Pereira Luis Moreno mató de una patada a una lechuza en el Estadio Metropolitano de Barranquilla; indudablemente, fue un acto deplorable. Sin embargo, más reprochable aún es la regresión de los valores que sufre el país, los cuales fueron evidenciados con este hecho.

El show de todos los noticieros mostraba a la lechuza debatiéndose entre la vida y la muerte; la lechuza en su contexto sobrevolando la sede del Júnior; las pancartas en la Plaza de Bolívar de Bogotá, exigiendo la expulsión del verdugo; los taxistas indignados, la declaración de persona no grata de los pereiranos a su jugador y hasta una solicitud de expulsión del fútbol colombiano a tan despiadado asesino. Las redes sociales colapsaron por la indignación manifiesta. Ese mismo día, sólo un par de horas después, hinchas del Santa Fe apuñalaron a Carlos Eduardo Pulido, joven de 17 años, porque portaba una gorra y una camiseta de Millonarios. El joven murió. Una familia se destrozó y a nadie le importó. No hubo ninguna pancarta. Nadie protestó. Las redes sociales no lo comentaron y la noticia se perdió entre las otras. No fue más que uno de los tantos hinchas asesinados en uno de tantos domingos. ${ }^{14}$

¿Tan torcida está la lógica de nuestros valores, que todo un país se indigna por la muerte de una lechuza, pero ni un ápice le importa la muerte de un menor apuñalado por una horda fanática?

\section{Aporía MORAL EN EL LABERINTO DEL ATAJO}

¿Qué es la cultura del atajo? La cultura del atajo comprende un conjunto de normas y valores que estimulan $y$, de cierto modo, justifican hacer lo que no es correcto, o aquello que no es conveniente, pero que se aceptan en aras de obtener una presunta eficacia, una inmediatez que busca lograr una aprobación mayoritaria de la sociedad (incluso legitimando mediante una aceptabilidad social algo que no es legal, ni tiene validez).

$\mathrm{El}$ atajo ha oscilado históricamente y se presenta en la sociedad latinoamericana, permeando todos los estratos, fundamentalmente por ausencia de identidad.

14 Diana Giraldo. La moral lechuza. Vanguardia liberal. Marzo 6 de 2011.
Esta pérdida de identidad la describe Rubén Blades en la composición musical "Buscando América". En una de sus estrofas da cuenta de esta realidad: "Te estoy buscando América y temo no encontrarla / Tus huellas se han perdido entre la oscuridad / Te estoy llamando América pero no me respondes / Te han desaparecido los que temen la verdad". ${ }^{15}$

No deja de ser patética tal referencia, que corrobora en uno de sus escritos el célebre periodista argentino Tomás Eloy Martínez, quien narró una anécdota del poder presidencial, en la cual se refleja la cultura del atajo:

Cuatro décadas atrás, en su retiro de Puerta de Hierro, Juan Perón corrigió el refrán que solía repetir cuando era presidente "la única verdad es la realidad", con una fábula que le había oído contar a su abuela Dominga.

"Observa los ojos de la mosca", dijo la abuela. "Son enormes. Ocupan casi toda la cabeza. Tienen $4.000 \mathrm{fa}$ cetas. ¿Qué ve la mosca, Juan? ¿Ve 4.000 verdades o una verdad partida en 4.000 pedazos?”. Cristina Fernández de Kirchner (presidenta de Argentina), respondió, con un énfasis que aleja cualquier tentación de réplica, que las verdades pueden ser 4.000 , pero que sólo una vale: la que ella ve. ${ }^{16}$

El uso del atajo se da institucionalmente o por fuera de la institucionalidad. Colombia no escapa de ello. En la parafernalia de un consejo comunitario realizado en Mitú, el presidente Uribe fue abordado por una indígena quien le contó que vivía hace trece años en el Vaupés y que estaba casada por lo civil, por lo católico y a través de un ritual indígena con un indígena macuna. Sin embargo, como en Mitú no había oficina de la Cancillería, ella no tenía la ciudadanía colombiana que tanto quería. El mandatario, después de preguntarle cuántos hijos tenía a la indígena y de decirle que con tres matrimonios con la misma persona esa unión era indisoluble, le reiteró enfática e imperativamente que el canciller le tendría que dar la nacionalidad colombiana ese mismo día. El más desprevenido ciudadano aplaudiría la eficacia presidencial, por cuanto su decisión daría lugar a pensar que es una acción eficaz, fácil, sin tramitomanías, sin importar las consecuencias de las acciones. ¿Acaso importa el Estado de derecho cuando el poder es portador de una sugestiva solución? ¿Acaso construir un atajo se justifica ante la rigidez que implica la legalidad? ¿Acaso el poder es inmune ante el

15. Rubén Blades. América. Buscando AméricA, Sello Elektra. (1984).

16. Tomás Eloy Martínez. Los ojos de mosca. El Espectador. Agosto 1 de 2009. 
uso del atajo? No estamos lejos de pensar, doscientos años después, que la metamorfosis del poder sigue cabalgando en el alma colectiva de la sociedad, cruzando raudamente por encima de la legalidad de la sociedad contemporánea.

\section{REFERENCIAS}

Corte Constitucional de Colombia. Sentencia C-224 DE 1994. (M. P. Jorge Arango Mejía; mayo 5 de 1994). Disponible en http://www.alcaldiabogota.gov.co/sisjur/ normas/Norma1.jsp? $\mathrm{i}=15892$

Corte Constitucional de Colombia. Sentencia C-373 DE 2002. (M. P. Jaime Córdoba Triviño; mayo 15 de 2002). Disponible en http://www.corteconstitucional.gov.co/ relatoria/2002/c-373-02.htm

Diana Giraldo. La moral lechuza. VANgUARdia LIBERAL. Marzo 6 de 2011.

Editorial. Libertad de expresión y protección a las minorías. EL Espectador. Marzo 6 de 2011.
Immanuel Kant. Metafísica DE LAS costumbres. Editorial Porrúa. (2001).

Immanuel Kant. Sobre un presunto derecho de mentir por filantropía. TeOríA Y PRÁCTICA. Editorial Tecnos. (2006).

John Rawls. Teoría DE LA JUSTiCiA. Editorial Fondo de Cultura Económica. (1995).

Ley 153 de 1887. Por la cual se adiciona y reforma los códigos nacionales, la ley 61 de 1886 y la 57 de 1887 . Agosto 15 de 1887 . Do N. ${ }^{\circ} 7151$ y 7152.

Rubén Blades. América. Buscando AméricA, Sello Elektra. (1984).

Sócrates y el buen ciudadano. EL Espectador. Febrero 24 de 2012. Disponible en: http://www.elespectador.com/ opinion/socrates-y-el-buen-ciudadano

Theodor Viehweg. TópICA y Jurisprudencia. Editorial Taurus. (1964).

Tomás Eloy Martínez. Los ojos de mosca. El Espectador. Agosto 1 de 2009.

Umberto Eco. El clásico acertijo del asesino en la puerta. EL EsPectador. Febrero 19 de 2012. 